\title{
O Uso do Kmplot como Ferramenta no Estudo de Gráficos de Derivadas e Integrais
}

\author{
André Felipe Costa de Carvalho, Gabriel Fernando Costa da Silva \\ Universidade Federal do Pará, Faculdade de Matemática \\ 68600-000, Bragança, PA \\ E-mails: andre.felipe.af@hotmail.com; gabriel_ferna@ hotmail.com.br
}

\author{
Alessandra Mariana dos Santos Oliveira \\ Universidade Federal do Pará, Faculdade de Matemática \\ 68600-000, Bragança, PA \\ E-mail: alessandra@ufpa.br
}

\begin{abstract}
RESUMO
A tecnologia não apenas facilita a vida do ser humano, mas ela já é uma parte indispensável do seu dia-a-dia. "As tecnologias, em suas diferentes formas e usos, constituem um dos principais agentes de transformação da sociedade" [1]. No processo de educação não é diferente, a tecnologia é mais um recurso que o professor tem para estimular o aluno a aprender, tornando suas aulas mais interessantes e diferenciadas. Existem diversos softwares livres que ajudam no processo educacional da Matemática, tais como: Geogebra, Kmplot, Régua e Compasso, Máxima, Wingeon, entre outros.

A disciplina de Cálculo Diferencial e Integral do curso de Licenciatura em Matemática necessita de bastante atenção visto que, segundo uma coleta indireta nos arquivos da Faculdade de Matemática do Campus Universitário de Bragança, observou-se que há uma grande dificuldade dos alunos nesta disciplina, por ser de grande complexidade. Visando mudar este cenário e o desenvolvimento dos alunos do curso, surgiu a proposta de elaborar um minicurso com duração de quatro horas, tendo a finalidade de minimizar as dificuldades no aprendizado do conteúdo, utilizando para isso o auxílio do Kmplot, que é um software de domínio público no qual é possível analisar graficamente as derivadas de primeira e segunda ordem e as integrais definidas.

O Kmplot é um software livre que pode ser feito o download e instalado no Sistema Operacional Linux, sendo que ele já vem integrado ao Linux Educacional. Sua funcionalidade básica é desenhar gráficos de funções que podem ser do tipo: explícitas, implícitas, paramétricas, polares e diferenciais. É uma ferramenta que auxilia na visualização e análise de gráficos sendo um facilitador no processo de ensino aprendizagem da matemática.

A importância do software livre na educação é justificável, pois, considerando o "ponto de vista macroeconômico, a adoção do software livre permite reduzir drasticamente o envio de royalties pelo pagamento de licenças de software, gerando maior sustentabilidade do processo de inclusão digital" [4]. Além disso, procura-se evitar práticas ilegais como a pirataria, tornando viável a utilização deste software na educação, haja vista que erros no programa servem de incentivo para melhorá-lo, pois este pertence a uma comunidade. Outro motivo é que o programa pode ser executado, copiado e modificado de acordo com as necessidades ou interesses de cada usuário e com liberdade de redistribuição.

Segundo [2] o acesso ao computador deve estar inserido em atividades essenciais como aprender a ler, por exemplo, e o contato com a informática contribui para uma "alfabetização tecnológica". Com a inserção de novas tecnologias, o aprendizado passa a ser mais significativo para o aluno fazendo com que este seja mais interativo, sendo o ator principal no processo de ensino aprendizagem. Conforme ainda [2], em sua obra "muitos advogam o uso do computador devido à motivação que ele traria à sala de aula, [...] o seu uso na educação poderia ser a solução para a falta de motivação dos alunos".
\end{abstract}


Definindo então as atividades a serem desenvolvidas no minicurso, foi feita inicialmente uma introdução ao cálculo através de conceitos de derivadas e integrais definidas, mostrando alguns exemplos numéricos. A seguir, foi apresentada a interface do programa, suas funcionalidades e ferramentas, onde uma destas ferramentas permite a análise gráfica de derivadas e integrais de uma função, em que as mesmas foram calculadas manualmente e, com o auxilio do software, foi feita a verificação dos resultados.Para demonstração do uso de derivadas, destacou-se como atividade a representação gráfica da equação da reta tangente a uma curva, sendo dados a equação da curva e um ponto (Figura 1). Para o caso das integrais, foi demonstrado o seu significado gráfico, onde uma integral definida representa numericamente a área da região sob o gráfico no intervalo (Figura 2).

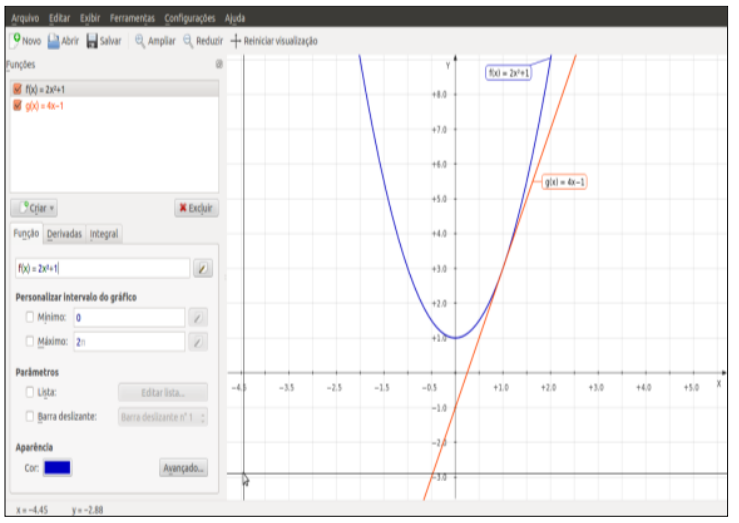

Figura 1 - Reta Tangente

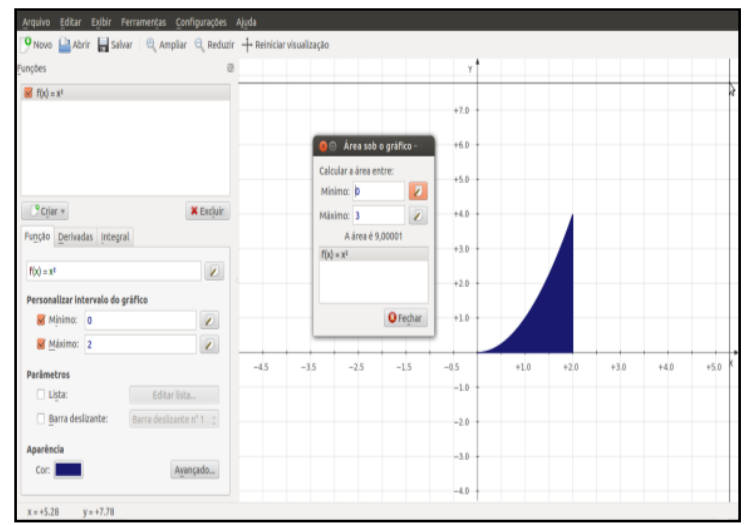

Figura 2 - Cálculo de Área

Após o desenvolvimento da atividade, percebeu-se que ouso do Kmplot proporcionou uma melhor visualização no comportamento dos gráficos de derivadas e integrais de funções, sendo o programa um auxiliador na análise dos resultados. O software foi bastante aceito pelos alunos do curso de Matemática, facilitando o processo de ensino aprendizagemdos conteúdos.

Palavras-chave: Kmplot, Software Livre, Derivada e Integral.

\section{REFERÊNCIAS}

[1] S. E. F. Brasil. "Parâmetros Curriculares Nacionais: Matemática”. Brasília: MEC/SEF, 1998.

[2] M. C. Borba, M. G. Penteado, "Informática e Educação Matemática". 3a ed., Belo Horizonte: Autêntica, 2003.

[3] K. D. Moller. Manual do KmPlot. Disponível em: docs.kde.org/stable/pt_BR/kdeedu/ kmplot/kmplot.pdf.

[4] S. A. Silveira, "Software Livre: a luta pela liberdade do conhecimento". São Paulo: Editora Fundação Perseu Abramo, 2004. 